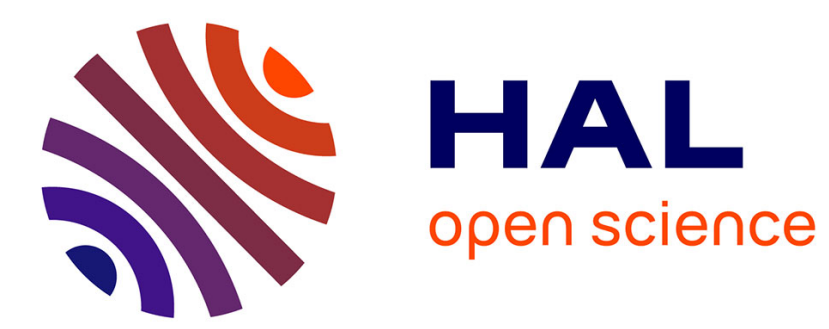

\title{
KGmax curves associated with second generation intact stability criteria for different types of ships
}

\author{
François Grinnaert, Jean-Yves Billard, Jean-Marc Laurens
}

\section{To cite this version:}

François Grinnaert, Jean-Yves Billard, Jean-Marc Laurens. KGmax curves associated with second generation intact stability criteria for different types of ships. Journal of Marine Science and Application, 2016, 15 (3), pp.223-235. 10.1007/s11804-016-1369-3 . hal-01410435

\section{HAL Id: hal-01410435 \\ https://hal.science/hal-01410435}

Submitted on 6 Dec 2016

HAL is a multi-disciplinary open access archive for the deposit and dissemination of scientific research documents, whether they are published or not. The documents may come from teaching and research institutions in France or abroad, or from public or private research centers.
L'archive ouverte pluridisciplinaire HAL, est destinée au dépôt et à la diffusion de documents scientifiques de niveau recherche, publiés ou non, émanant des établissements d'enseignement et de recherche français ou étrangers, des laboratoires publics ou privés. 


\title{
KG $_{\max }$ Curves Associated With Second Generation Intact Stability Criteria for Different Types of Ships
}

\author{
Francois Grinnaert $^{1 *}$, Jean-Yves Billard ${ }^{1}$ and Jean-Marc Laurens $^{2}$ \\ 1. French Naval Academy Research Institute, Brest 29240, France \\ 2. ENSTA Bretagne, Brest 29200, France
}

\begin{abstract}
Currently, second generation intact stability criteria are being developed and evaluated by the International Maritime Organization (IMO). In this paper, we briefly present levels 1 and 2 assessment methods for the criteria of pure loss of stability and parametric roll failure modes. Subsequently, we show the $\mathrm{KG}_{\max }$ curves associated with these criteria. We compute these curves for five different types of ships and compare them with the curves embodied in the current regulations. The results show that the safety margin ensured by the first level-1 method of calculation for both pure loss of stability and parametric roll seems to be excessive in many cases. They also show that the $\mathrm{KG}_{\max }$ given by the second level-1 method and by the level-2 method may be very similar. In some cases, the level-2 method can be more conservative than the second level-1 method, which is unanticipated by the future regulation. The $\mathrm{KG}_{\max }$ curves associated with parametric roll confirm that the $\mathrm{C} 11$ container ship is vulnerable to this failure mode. The computation of the second check coefficient of parametric roll level $2(\mathrm{C} 2)$ for all possible values of $\mathrm{KG}$ reveals the existence of both authorized and restricted areas on the surface formed by both the draft and KG, which may replace the classical $\mathrm{KG}_{\max }$ curves. In consequence, it is not sufficient to check that $\mathrm{C} 2$ is lower than the maximum authorized value $\left(R_{\mathrm{PR} 0}\right)$ for a fixed ship's loading condition.

Keywords: pure loss of stability, parametric roll, $\mathrm{KG}_{\max }$ curve, second generation intact stability criteria
\end{abstract}

Article ID: 1671-9433(2016)03-0223-13

\section{Introduction}

Secondgeneration intact stability criteria are currently being developed and evaluated by the International Maritime Organization (IMO) (Bassler et al., 2009, Francescutto and Umeda, 2010, Wandji and Corrignan, 2012). These criteria were presented in detail at the $13^{\text {th }}$ International Ship Stability Workshop (Umeda, 2013). In this paper, we address this version, as amended in February 2015 and January 2016 by the Sub-Committee on Ship Design and Construction of the IMO (SDC 2/WP.4 and SDC 3/WP.5). The new criteria are structured in five failure modes: pure loss of stability in astern waves, parametric roll, broaching/surf-riding, dead ship condition, and excessive acceleration. Three assessment levels are defined for each failure mode. The first level is based on a simplified deterministic approach of the phenomena and ensures high safety margins. A ship that does not pass this first level is designated as "unconventional" by the new regulation (Fig. 1). The second assessment level is based on probabilistic approaches to the phenomena. It requires more complex computations based on hydrostatic considerations with regard to static waves, and ensures medium safety margins. The third assessment level consists of numerical simulations of the ship's behavior on waves, as performed by specialized institutes. This last level ensures optimized safety margins. In order to comply with future rules, a ship must comply with current rules (IMO IS Code 2.2, 2009) and with at least one level of each failure mode (Fig. 1).

After a short presentation of the first and second level criteria of the pure loss of stability and parametric roll failure modes, in this paper, we show the curves of the maximum height of the center of gravity as a function of displacement ( $\mathrm{KG}_{\max }$ curves) with regard to the criteria of these two failure modes. We compute these curves for ships of five different types, chosen for their variety of behavior with regard to both failure modes: a naval ship, two container ships, a roll-on roll-off (Ro-Ro) vessel, and a tanker. $\mathrm{KG}_{\max }$ curves allow a crew to assess their ship's stability with regard to a specific criterion or several criteria (envelope curve) without the need to performa any complex computation. $\mathrm{KG}_{\max }$ curves are included in each ship's stability booklet. In this paper, the avoidance any assumption about the height of the center of gravity is permitted. This also enables a comparison of the results given by all levels and methods in order to determine the efficiency and relevance of the new criteria. We compare curves based on these new criteria with those based on the first-generation criteria. While not the main objective of this paper, the consideration of $\mathrm{KG}_{\max }$ curves allows for the determination of the vulnerability of vessels to these two failure modes. Similar studies have been performed (Krueger et al., 2013, 2015) but were based on former versions of the new criteria (respectively SLF 54/19, 2012 and SDC 1/INF.8, 2013). 


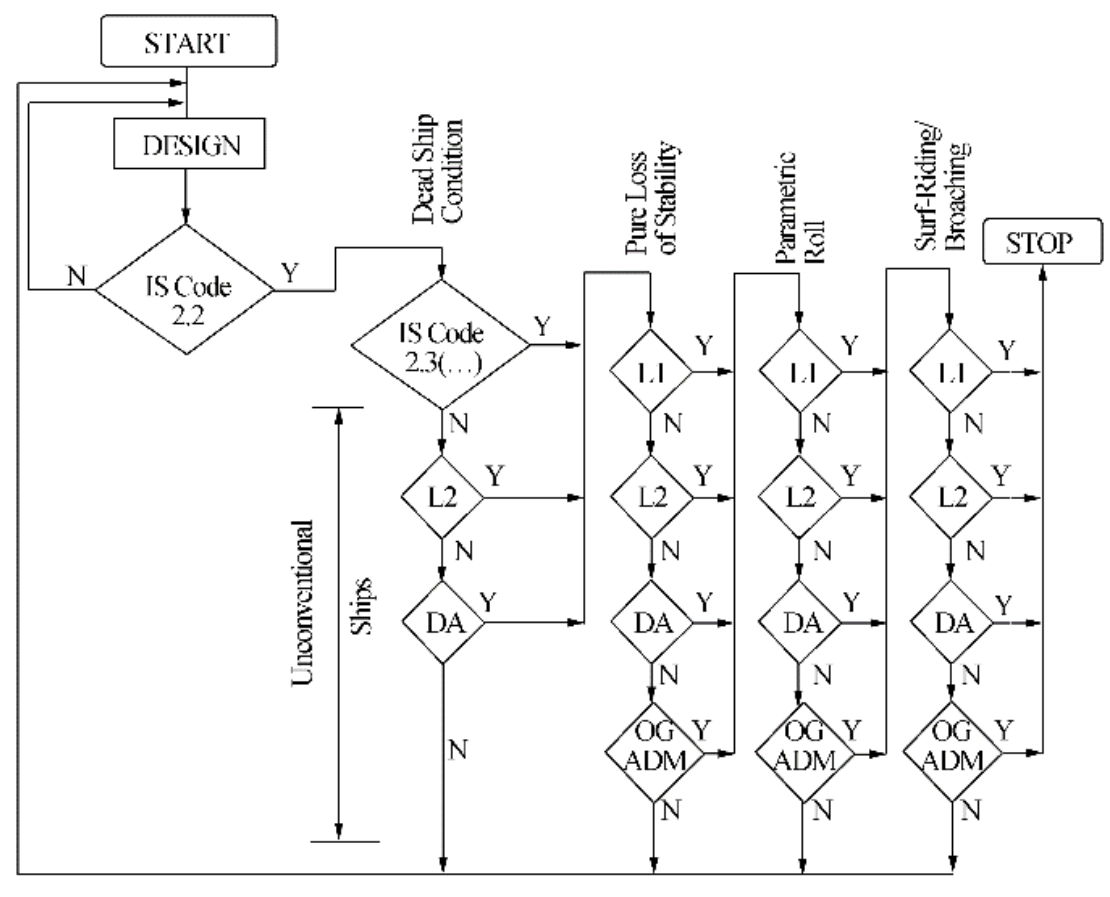

... WeC possibly amended with stecpness table from MSC.1/Circ. 1200

Fig. 1 Future intact stability regulation (Bulian and Francescutto, 2011)

\section{Presentation of ships}

The main particulars of the five ships in this study are given in Table 1. The superstructures of four of them have been modelled in order to compute the weather criterion (IS
Code 2.3, IMO, 2009), without taking into account their flooding points. The bilge keels of all the ships have also been modelled.

Table 1 Main particulars of ships

\begin{tabular}{|c|c|c|c|c|c|c|c|}
\hline Particular & Symbol & Unit & Naval ship & Container ship C11 & Container ship $319 \mathrm{~m}$ & Ro-Ro & Tanker \\
\hline Length overall & $L_{\mathrm{OA}}$ & $\mathrm{m}$ & 152.9 & 275.8 & 335.5 & 147.9 & 236.5 \\
\hline Length between perpendiculars & $L_{\mathrm{PP}}$ & $\mathrm{m}$ & 142 & 262 & 319 & 135 & 227.5 \\
\hline Breadth & $B$ & $\mathrm{~m}$ & 19.06 & 40 & 42.8 & 24.2 & 32.2 \\
\hline Draft, full load & $d_{\text {full }}$ & $\mathrm{m}$ & 6.15 & 12 & 13 & 5.50 & 11 \\
\hline Freeboard, full load & $f$ & $\mathrm{~m}$ & 3.85 & 12.45 & 11.60 & 12.50 & 7.00 \\
\hline Displacement, full load & $\Delta$ & $\mathrm{t}$ & 8634 & 73340 & 107350 & 11544 & 70397 \\
\hline Speed & $V_{s}$ & kts & 30 & 20 & 25 & 20 & 15 \\
\hline Froude number & $F n$ & - & 0.413 & 0.203 & 0.230 & 0.283 & 0.163 \\
\hline Block coefficient & $C_{b}$ & - & 0.507 & 0.569 & 0.590 & 0.625 & 0.852 \\
\hline Bilge keels length & $L_{\mathrm{bk}}$ & $\mathrm{m}$ & 35.7 & 76.53 & 81 & 45 & 75 \\
\hline Bilge keels breadth & $B_{\mathrm{bk}}$ & $\mathrm{m}$ & 0.55 & 0.40 & 0.50 & 0.30 & 0.30 \\
\hline Bilge keels projected area & $A_{\mathrm{k}}$ & $\mathrm{m}^{2}$ & 34.009 & 58.023 & 57.276 & 19.092 & 31.82 \\
\hline Added mass coefficient $\left.{ }^{*}\right)$ & $a$ & - & 0.1 & 0.1 & 0.1 & 0.094 & 0.1 \\
\hline Radius of inertia coefficient ${ }^{(*)}$ & $k$ & - & 0.4 & 0.429 & 0.4 & 0.41 & 0.4 \\
\hline Reference height of G & $\mathrm{KG}_{\mathrm{ref}}$ & $\mathrm{m}$ & 7.998 & 18.239 & 18 & 12.215 & 12 \\
\hline Metacentric height @ $\mathrm{KG}_{\text {ref }}$ & $\mathrm{GM}_{\mathrm{ref}}$ & $\mathrm{m}$ & 1.5 & 1.973 & 2.174 & 1.638 & 1.7 \\
\hline Roll period @ $\mathrm{KG}_{\mathrm{ref}}$ & $T_{0}$ & $\mathrm{~s}$ & 14.12 & 25.7 & 24.43 & 16.27 & 20.78 \\
\hline Starting value of $\mathrm{KG}^{(*)}$ & $\mathrm{KG}_{\text {start }}$ & $\mathrm{m}$ & 7.00 & 14.00 & 15.00 & 9.00 & 10.00 \\
\hline Pure loss limit angle ${ }^{(*)}$ & $R_{\text {PL2 }}$ & - & 25 & 25 & 25 & 25 & 25 \\
\hline GM variation $\left.\operatorname{limit}^{*}\right)$ & $R_{\mathrm{PR}}$ & - & 0.418 & 0.405 & 0.348 & 0.418 & 0.355 \\
\hline Roll damping coefficient & $B_{44}$ & \multicolumn{2}{|c|}{$\mathrm{N} \cdot \mathrm{m} \cdot \mathrm{s} / \mathrm{rad} 4.018 \mathrm{e} 7$} & $1.027 \mathrm{e} 9$ & $1.099 \mathrm{e} 9$ & $1.721 \mathrm{e} 8$ & $2.463 \mathrm{e} 8$ \\
\hline Superstructures & - & - & Yes & Yes & Yes & No & Yes \\
\hline
\end{tabular}

Data marked with $(*)$ are defined later in this paper. 
The first ship is the David Taylor Model Basin hull number 5415, a naval ship presented by Moelgaard (2000). Included in her model are superstructure concepts inspired by those of the DDG51 Arleigh Burke.

The second ship is the C11 container ship, which is known to be vulnerable to parametric roll (France et al., 2001).

The third ship is a $319 \mathrm{~m}$ container ship. A fatal accident due to an extreme roll motion (not a parametric roll) occurred on a ship of this class in 2008. One of the causes determined by the experts was insufficient roll damping (Kaufmann, 2009). Numerical models of both container ships include the containers in full-load configuration.

The fourth ship is a Ro-Ro vessel presented by Garme (1997). Data for this ship have been provided by the KTH Royal Institute of Technology. Her superstructure has not been modelled. The $\mathrm{KG}_{\max }$ curve associated with the first-generation criteria does not take weather criterion into account.

We chose the last ship from the DELFT ship database-a tanker that is wall-sided on $80 \%$ of her length - for her supposed non-vulnerability to both pure loss of stability and parametric roll. A simplified box-shaped superstructure was added to her model but has no influence on the $\mathrm{KG}_{\max }$ curve associated with the current criteria.

We used the reference height of the center of gravity $\left(\mathrm{KG}_{\mathrm{ref}}\right)$ to calculate the associated metacentric height in calm water (GMref) and natural roll period $\left(T_{0}\right)$ for each ship. The latter depends on the added mass coefficient and the radius of inertia coefficient ( $a$ and $k$, as defined in subsection 4.2.1). The roll period is given for the full-load displacement, except for the $\mathrm{C} 11$ container ship, whose associated draft is $12.339 \mathrm{~m}$ (France et al., 2001). We calculated the roll damping coefficient $B_{44}$ as described in subsection 4.2.2. Its value is given for the reference height of the center of gravity $\left(\mathrm{KG}_{\mathrm{ref}}\right)$, the full load draft $(12.339 \mathrm{~m}$ for the $\mathrm{C} 11$ container ship), the service speed $(V s)$, and a roll amplitude of 10 degrees.

\section{Pure loss of stability failure mode}

\subsection{Presentation of criteria}

Here, we briefly present the first- and second-level criteria for the pure loss of stability failure mode. These criteria are applied to ships having a service speed Froude number larger than 0.24 . Although neither container ship nor the tanker fulfill this condition, we computed their $\mathrm{KG}_{\max }$ curves that are associated with the levels 1 and 2 criteria.

\subsubsection{First level}

To meet this criteria level, the minimum metacentric height in waves $\left(\mathrm{GM}_{\min }\right)$ must be higher than 5 centimeters. The new regulation proposes two methods to calculate its value.

The first method considers a parallel water-plane area at the lowest draft $d_{L}$ :

$$
d_{L}=d-\left(d-0.25 d_{\text {full }} ; \frac{L S_{W}}{2}\right)
$$

with:

d (m) draft corresponding to the loading condition in calm water (black line in Fig. 2);

$d_{\text {full }} \quad$ (m) draft, full load;

$L \quad$ (m) ship's length;

$S_{W} \quad 0.0334$ wave steepness.

In most cases, the lowest draft can be simplified as follows:

$$
d_{L}=d-\frac{L S_{W}}{2}
$$

The minimum metacentric height is calculated as follows:

$$
\mathrm{GM}_{\min }=\mathrm{KB}+\frac{I_{L}}{\nabla}-\mathrm{KG}
$$

with:

KB (m) height of the vertical center of buoyancy in calm water;

$I_{L} \quad\left(\mathrm{~m}^{4}\right) \quad$ moment of inertia of the water-plane area at lowest draft $d_{L}$ (gray area in Fig. 2);

$\nabla \quad\left(\mathrm{m}^{3}\right) \quad$ volume of displacement;

KG (m) height of the vertical center of gravity.

This method considers that the moment of inertia of the water-plane area in waves is similar to that of the parallel water-plane area at the lowest draft $d_{L}$ (gray area in Fig. 2).

In the second method, the minimum metacentric height is computed for the ship balanced in trim and sinkage on sinusoidal waves. The wave length is equal to the ship's length $L$ and the height is $h=S_{W} L$. The wave crest is centered at the longitudinal center of gravity and at each $L / 10$ forward and aft.

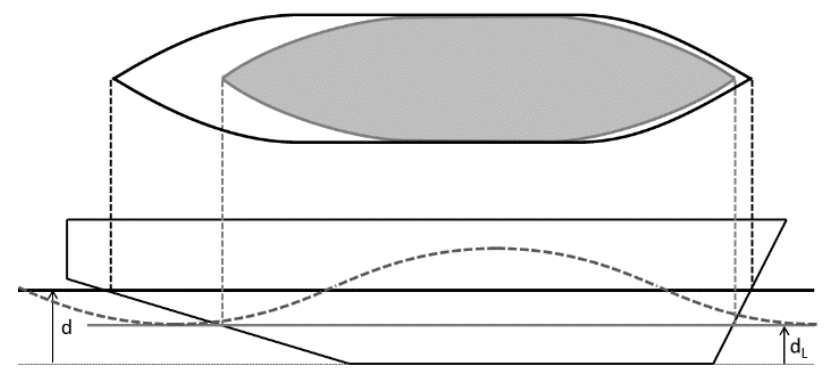

Fig. 2 Parallel water-plane at the lowest draft $d_{L}$

\subsubsection{Second Level}

Determination of the second-level criterion consists of a probabilistic approach to the phenomenon, associated with a wave scattering table. For an unrestricted sailing area, the new regulation imposes that found in the IACS Recommendation No. 34 (2001), which corresponds with the Northern Atlantic Table 2. This table lists 16 wave periods and 17 wave heights, and 197 waves have a non-zero number of occurrence. The new regulation allows for the use of another wave scattering table if the ship is sailing in a restricted area. 
Table 2 Wave scatter diagram (from IACS, 2001)

\begin{tabular}{|c|c|c|c|c|c|c|c|c|c|c|c|c|c|c|c|c|}
\hline \multirow[b]{2}{*}{$H_{S} / \mathrm{m}$} & \multicolumn{15}{|c|}{ Number of occurrences: $100000 / T_{Z}(s)=$ average zero up-crossing wave period } & \multirow[b]{2}{*}{18.5} \\
\hline & 3.5 & 4.5 & 5.5 & 6.5 & 7.5 & 8.5 & 9.5 & 10.5 & 11.5 & 12.5 & 13.5 & 14.5 & 15.5 & 16.5 & 17.5 & \\
\hline 0.5 & 1.3 & 133.7 & 865.6 & 1186 & 634.2 & 186.3 & 36.9 & 5.6 & 0.7 & 0.1 & 0 & 0 & 0 & 0 & 0 & 0 \\
\hline 1.5 & 0 & 29.3 & 986 & 4976 & 7738 & 5569.7 & 2375.7 & 703.5 & 160.7 & 30.5 & 5.1 & 0.8 & 0.1 & 0 & 0 & 0 \\
\hline 2.5 & 0 & 2.2 & 197.5 & 2158.8 & 6230 & 7449.5 & 4860.4 & 2066 & 644.5 & 160.2 & 33.7 & 6.3 & 1.1 & 0.2 & 0 & 0 \\
\hline 3.5 & 0 & 0.2 & 34.9 & 695.5 & 3226.5 & 5675 & 5099.1 & 2838 & 1114.1 & 337.7 & 84.3 & 18.2 & 3.5 & 0.6 & 0.1 & 0 \\
\hline 4.5 & 0 & 0 & 6 & 196.1 & 1354.3 & 3288.5 & 3857.5 & 2685.5 & 1275.2 & 455.1 & 130.9 & 31.9 & 6.9 & 1.3 & 0.2 & 0 \\
\hline 5.5 & 0 & 0 & 1 & 51 & 498.4 & 1602.9 & 2372.7 & 2008.3 & 1126 & 463.6 & 150.9 & 41 & 9.7 & 2.1 & 0.4 & 0.1 \\
\hline 6.5 & 0 & 0 & 0.2 & 12.6 & 167 & 690.3 & 1257.9 & 1268.6 & 825.9 & 386.8 & 140.8 & 42.2 & 10.9 & 2.5 & 0.5 & 0.1 \\
\hline 7.5 & 0 & 0 & 0 & 3 & 52.1 & 270.1 & 594.4 & 703.2 & 524.9 & 276.7 & 111.7 & 36.7 & 10.2 & 2.5 & 0.6 & 0.1 \\
\hline 8.5 & 0 & 0 & 0 & 0.7 & 15.4 & 97.9 & 255.9 & 350.6 & 296.9 & 174.6 & 77.6 & 27.7 & 8.4 & 2.2 & 0.5 & 0.1 \\
\hline 9.5 & 0 & 0 & 0 & 0.2 & 4.3 & 33.2 & 101.9 & 159.9 & 152.2 & 99.2 & 48.3 & 18.7 & 6.1 & 1.7 & 0.4 & 0.1 \\
\hline 10.5 & 0 & 0 & 0 & 0 & 1.2 & 10.7 & 37.9 & 67.5 & 71.7 & 51.5 & 27.3 & 11.4 & 4 & 1.2 & 0.3 & 0.1 \\
\hline 11.5 & 0 & 0 & 0 & 0 & 0.3 & 3.3 & 13.3 & 26.6 & 31.4 & 24.7 & 14.2 & 6.4 & 2.4 & 0.7 & 0.2 & 0.1 \\
\hline 12.5 & 0 & 0 & 0 & 0 & 0.1 & 1 & 4.4 & 9.9 & 12.8 & 11 & 6.8 & 3.3 & 1.3 & 0.4 & 0.1 & 0 \\
\hline 13.5 & 0 & 0 & 0 & 0 & 0 & 0.3 & 1.4 & 3.5 & 5 & 4.6 & 3.1 & 1.6 & 0.7 & 0.2 & 0.1 & 0 \\
\hline 14.5 & 0 & 0 & 0 & 0 & 0 & 0.1 & 0.4 & 1.2 & 1.8 & 1.8 & 1.3 & 0.7 & 0.3 & 0.1 & 0 & 0 \\
\hline 15.5 & 0 & 0 & 0 & 0 & 0 & 0 & 0.1 & 0.4 & 0.6 & 0.7 & 0.5 & 0.3 & 0.1 & 0.1 & 0 & 0 \\
\hline 16.5 & 0 & 0 & 0 & 0 & 0 & 0 & 0 & 0.1 & 0.2 & 0.2 & 0.2 & 0.1 & 0.1 & 0 & 0 & 0 \\
\hline
\end{tabular}

A ship is found to be not vulnerable to pure loss of stability if both CR1 and CR2 values are lower than $R_{\mathrm{PL} 0}=$ 0.06. CR1 and CR2 are computed as follows:

$$
\mathrm{CR} 1=\sum_{i=1}^{197} W_{i} \mathrm{Cl}_{i} \quad \mathrm{CR} 2=\sum_{i=1}^{197} W_{i} \mathrm{C} 2_{i}
$$

with:

$W i$ weighting factor of the wave number i taken from Table 2 (number of occurrences divided by 100,000);

$\mathrm{Cl}_{\mathrm{i}}$ coefficient for the wave number $i$ regarding the minimum angle of vanishing stability $\Phi_{V \text { min }}$ (Fig. 3);

$\mathrm{C} 2 \mathrm{i}_{\mathrm{i}}$ coefficient for the wave number $i$ regarding the maximum angle of stable equilibrium $\Phi_{\text {S.max }}$ under action of a heeling lever $R_{\text {PL3 }}$ (Fig. 3).

Waves are assumed to be sinusoidal. Their heights are taken from Table 2 ( $H_{S}$ is twice the wave amplitude), and their lengths $\lambda$ are linked to their zero-crossing periods $T_{Z}$ (Table 2) by the infinite depth relation given by:

$$
\lambda=\frac{g T_{Z}^{2}}{2 \pi}
$$

For each wave, the heeling lever $R_{P L 3}$ is defined as follows:

$$
R_{P L 3}=8 \frac{H_{s}}{\lambda} d F_{n}^{2}
$$

Then the minimum angle of vanishing stability $\left(\Phi_{V . \mathrm{min}}\right)$ and the maximum angle of stable equilibrium $\left(\Phi_{S \text {.max }}\right)$ are computed for the 197 non-zero-weighted waves of the wave scatter diagram, and used these values to calculate $\mathrm{C}_{i}$ and $\mathrm{C} 2{ }_{i}$ as follows:

$$
\begin{aligned}
\mathrm{Cl}_{i} & =\left\{\begin{array}{lc}
1 & \text { if } \Phi_{V \cdot \min }<R_{P L 1} \\
0 & \text { otherwise }
\end{array}\right. \\
\mathrm{C} 2_{i} & =\left\{\begin{array}{lc}
1 & \text { if } \Phi_{S \cdot \min }<R_{P L 2} \\
0 & \text { otherwise }
\end{array}\right.
\end{aligned}
$$

with:
$R_{\text {PL1 }} 30$ degrees;

$R_{\text {PL2 }} 25$ degrees (15 degrees for passenger ships).

Since there are a large number of non-zero-weighted waves, the new regulation proposes a method to make the computation faster, based on Grim's effective wave height concept (1961). For each wave of Table 2 defined by its zero-crossing period $\left(T_{Z}\right)$ and significant height $\left(H_{S}\right)$, an effective height for the top $3 \%$ highest waves $H_{3 \%}$ eff is computed. It corresponds to an equivalent wave whose length $\lambda$ is equal to the ship's length $L$. The effective wave height is computed using the following formulae:

$$
\begin{gathered}
H_{3 \%}^{\text {eff }}=5.9725 \sqrt{m_{0}} \\
m_{0}=\int_{0.01 \omega_{L}}^{3 \omega_{L}}\left\{\frac{\frac{\omega^{2} L}{g} \sin \left(\frac{\omega^{2} L}{2 g}\right)}{\pi^{2}-\left(\frac{\omega^{2} L}{2 g}\right)^{2}}\right\}^{2} A \omega^{5} \exp \left(-B \omega^{-4}\right) \mathrm{d} \omega \\
A=173 H_{S}^{2} T_{01}^{-4} \\
B=691 T_{01}^{-4} \\
T_{01}=1.086 T_{Z} \\
\omega_{L}=\sqrt{\frac{2 g \pi}{L}}
\end{gathered}
$$

The minimum angle of vanishing stability $\left(\Phi_{V \cdot \min }\right)$ and the maximum angle of stable equilibrium $\left(\Phi_{S . \max }\right)$ are calculated for 11 effective waves with heights from zero to the maximum effective wave height corresponding to the ship's length and the IACS wave scatter diagram (Table 2). For each effective wave, $10 \mathrm{GZ}$ curves are computed, considering the ship balanced in trim and sinkage, and for the wave crest centered at the longitudinal center of gravity and at each $\lambda / 10$ forward and aft. Only one GZ curve is needed for the first wave, which corresponds to calm water. 
The values of $\Phi_{V \cdot \min }$ and $\Phi_{S \text {.max }}$ associated with any effective wave height are calculated using linear interpolation in the interval between two successive values of these 11 heights. Table 3 gives the effective wave heights (in meters) computed according to the Grim method for all the ships in this study, as associated with the waves of Table 2 having a zero-crossing period $\left(T_{Z}\right)$ equal to 10.5 seconds.

Table 3 Effective height of the top $3 \%$ highest waves (m) for a zero-crossing period of 10.5 seconds

\begin{tabular}{llllll}
\hline$H_{S} / \mathrm{m}$ & Naval & \multicolumn{3}{l}{ Container Container Ro-Ro } & Tanker \\
& $L=142 \mathrm{~m}$ & $L=262 \mathrm{~m}$ & $L=319 \mathrm{~m}$ & $L=135 \mathrm{~m}$ & $L=227.5 \mathrm{~m}$ \\
\hline 0.5 & 0.430 & 0.539 & 0.538 & 0.417 & 0.526 \\
1.5 & 1.289 & 1.618 & 1.614 & 1.251 & 1.579 \\
2.5 & 2.149 & 2.697 & 2.691 & 2.085 & 2.631 \\
3.5 & 3.008 & 3.776 & 3.767 & 2.919 & 3.683 \\
4.5 & 3.868 & 4.855 & 4.843 & 3.753 & 4.736 \\
5.5 & 4.727 & 5.934 & 5.919 & 4.587 & 5.788 \\
6.5 & 5.587 & 7.013 & 6.996 & 5.421 & 6.841 \\
7.5 & 6.446 & 8.092 & 8.072 & 6.255 & 7.893 \\
8.5 & 7.306 & 9.171 & 9.148 & 7.089 & 8.945 \\
9.5 & 8.165 & 10.250 & 10.225 & 7.923 & 9.998 \\
10.5 & 9.025 & 11.329 & 11.301 & 8.757 & 11.050 \\
11.5 & 9.884 & 12.408 & 12.377 & 9.591 & 12.103 \\
12.5 & 10.744 & 13.487 & 13.453 & 10.425 & 13.155 \\
13.5 & 11.603 & 14.566 & 14.530 & 11.258 & 14.207 \\
14.5 & 12.463 & 15.645 & 15.60 & 12.092 & 15.260 \\
15.5 & 13.322 & 16.724 & 16.682 & 12.926 & 16.312 \\
16.5 & 14.182 & 17.803 & 17.758 & 13.760 & 17.365 \\
\hline & & & & &
\end{tabular}

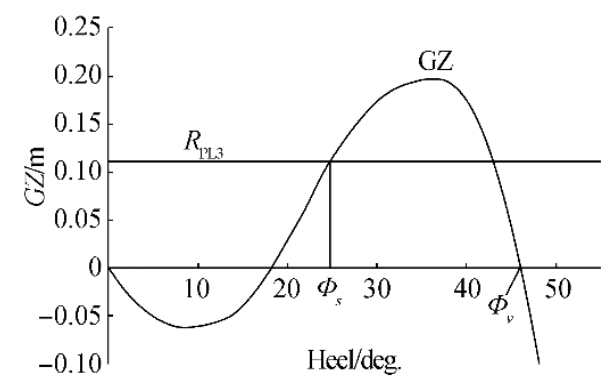

Fig. 3 Righting arm curve on static wave with angle of stable equilibrium under heeling lever $\operatorname{RPL}_{\mathrm{PL}}\left(\Phi_{S}\right)$ and angle of vanishing stability $\left(\Phi_{V}\right)$

\subsection{Results}

We computed the $\mathrm{KG}_{\max }$ curves associated with the pure loss of stability levels 1 and 2 criteria for the five ships in this study. Hydrostatic computations in calm water and static waves were made using Calcoque software, which is published in a handbook (Grinnaert and Laurens, 2013) and was presented at the $12^{\text {th }}$ International Conference on the Stability of Ships and Ocean Vehicles (Grinnaert et al., 2015). All computations were performed assuming a water density of $1.025 \mathrm{t} / \mathrm{m}^{3}$ and zero trim (the sinkage and trim remain free while the ships are balanced on waves). The $\mathrm{KG}_{\text {max }}$ curves are shown in Fig. 4 to Fig. 8.

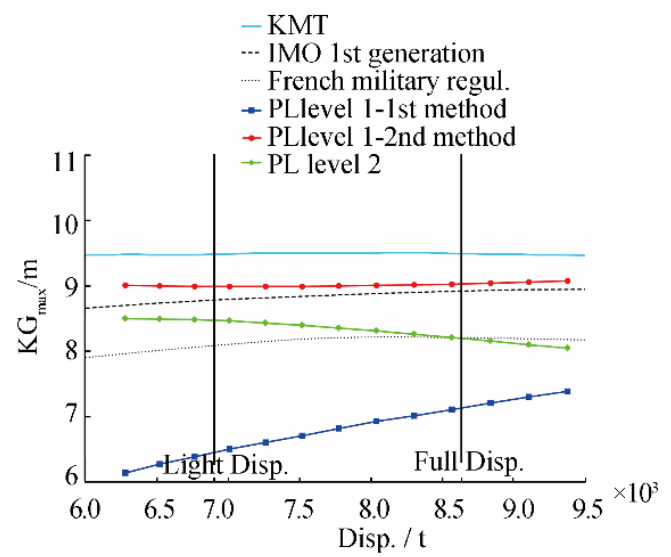

Fig. 4 KGmax curves associated with the pure loss of stability criteria for the naval ship

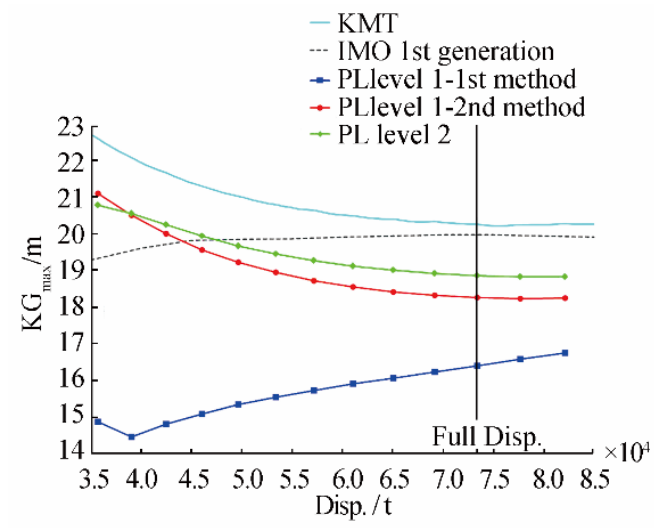

Fig. 5 KGmax curves associated with the pure loss of stability criteria for the $\mathbf{C} 11$ container ship

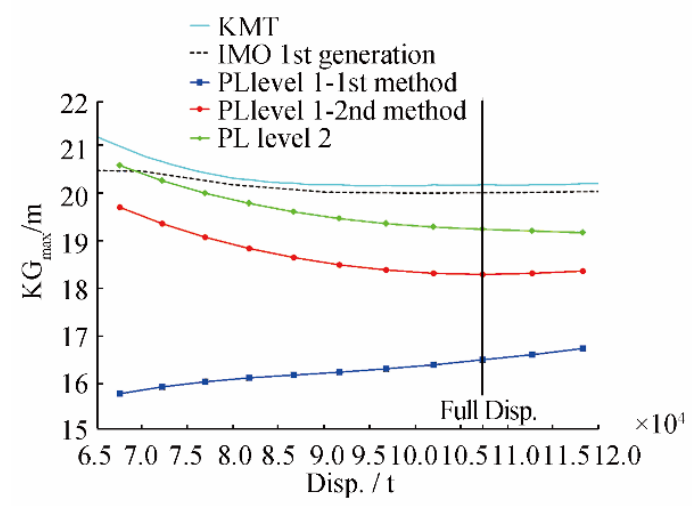

Fig. $6 \mathrm{KG}_{\max }$ curves associated with the pure loss of stability criteria for the 319 m container ship 


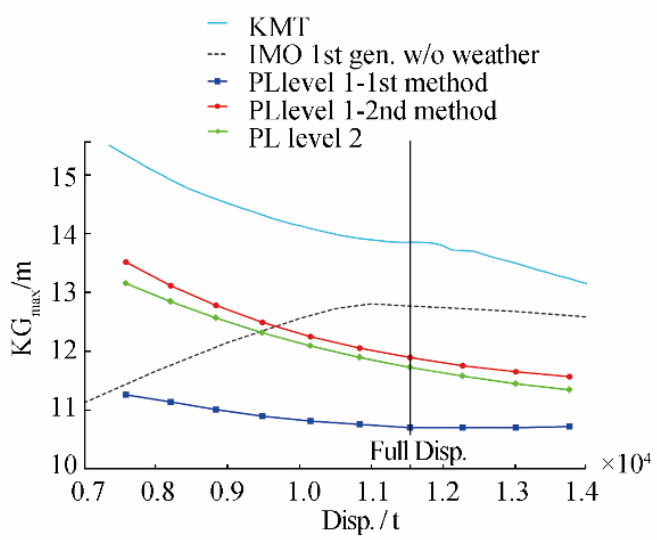

Fig. $7 \mathbf{K G}_{\max }$ curves associated with the pure loss of stability criteria for the Ro-Ro vessel

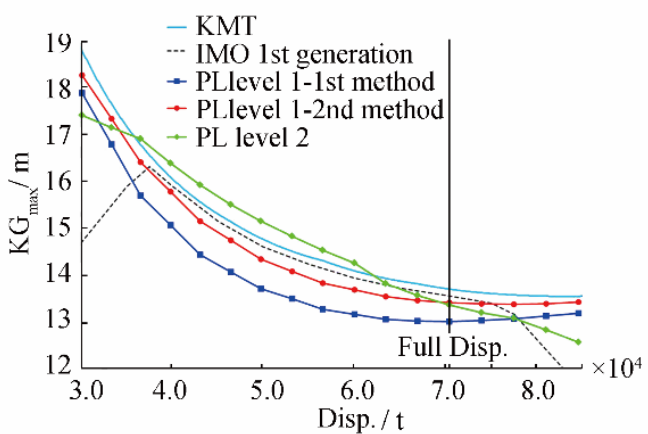

Fig. $8 \mathbf{K G}_{\max }$ curves associated with the pure loss of stability criteria for the tanker

Those associated with the first generation regulation (IMO, 2009) are given for all ships and are drawn as dashed lines. That associated with the French military regulation (IG 6018A, DGA, 1999) is given for the naval ship only (dotted line). Depending on the displacement, the vertical coordinate of the metacenter (KMT) is shown in all figures as a solid line to allow for the determination of the minimum GM required by all criteria. The vertical lines indicate full load displacement and, when known, the light displacement. The $\mathrm{KG}_{\max }$ curve determined by the first level-1 method (parallel water-plane) is marked "PL Level 1-1st method" in the figures (square markers). The $\mathrm{KG}_{\max }$ curve determined by the second level-1 method (ship balanced in trim and sinkage on a wave of the same length) is marked "PL Level 1-2nd method" (round markers). The $\mathrm{KG}_{\max }$ curve determined by the level-2 criterion is marked "PL Level 2" (diamond markers). A ship may be considered to be vulnerable to pure loss of stability if her $\mathrm{KG}_{\max }$ curve associated with the current regulation (civilian or military) is located above the highest curve associated with the pure loss of stability criteria (we formulated this consideration in this paper, for both pure loss of stability and parametric roll failure modes). From these figures, we can observe the following:

1) The two level-1 methods yield significantly different results for all vessels, except the tanker.

2) The $K_{\text {max }}$ value given by the second level-1 method is relatively close to that given by the level-2 method for the C11 container ship and the Ro-Ro vessel.

3) The level-2 method can yield more conservative results than the second level-1 method (by one point for the C11 container ship and more markedly for the naval ship and the Ro-Ro vessel). This is contrary to our understanding of the intent regarding future regulation.

4) The level-2 method allows for a negative GM for the tanker. This is due to the consideration of the GZ curve instead of GM in this criterion. Fig. 3 shows a GZ curve with a negative GM, which has a positive contribution to the criterion $\left(\mathrm{C}_{i}\right.$ and $\mathrm{C}_{2} i$ are not increased): $\Phi_{V}$ is larger than $R_{\mathrm{PL} 1}$ (30 degrees) and $\Phi_{S}$ is lower than $R_{\mathrm{PL} 2}$ (25 degrees)

5) According to these criteria, the naval ship and the tanker are not vulnerable to pure loss of stability, but both container ships are vulnerable, irrespective of the Froude number. No conclusions can be drawn with regard to the Ro-Ro vessel, since her superstructure has not been modelled and the weather criterion is not taken into account.

\section{Parametric roll failure mode}

\subsection{Presentation of criteria}

Next, we briefly present the first- and second-level criteria for the parametric roll failure mode. For more details please refer to SDC 2/WP.4 and SDC 3/WP.5.

\subsubsection{First level}

The first-level criteria of the parametric roll requires that the amplitude of the variation of the metacentric height in waves ( $\Delta \mathrm{GM}$ ) be less than $R_{\mathrm{PR}}$, whose value is between 0.17 (ship without a bilge keel) and 1.87 (ships with a large bilge keel). The new regulation proposes two methods for calculating $\Delta \mathrm{GM}$.

In the first method, two parallel water-planes are considered. The first is a low draft $\left(d_{L}\right)$ water-plane, and its moment of inertia is $I_{L}$. The second is a high draft $\left(d_{H}\right)$ water-plane, and its moment of inertia is $I_{H}$, with:

$$
\begin{gathered}
d_{L}=d-\min \left(d-0.25 d_{\text {full }} ; \frac{L S_{W}}{2}\right) \\
d_{H}=d+\min \left(D-d ; \frac{L S_{W}}{2}\right)
\end{gathered}
$$

$d \quad(\mathrm{~m}) \quad$ draft corresponding to the loading condition;

$d_{\text {full }} \quad(\mathrm{m}) \quad$ draft, full load;

$D \quad$ (m) ship's depth;

$L \quad$ (m) ship's length;

$S_{W} \quad 0.0167$ wave steepness

In most cases, both drafts can be simplified as follows:

$$
\begin{gathered}
d_{L}=d-\frac{L S_{W}}{2} \\
d_{H}=d+\frac{L S_{W}}{2}
\end{gathered}
$$

The amplitude of the variation of the metacentric height is calculated as follows: 


$$
\Delta \mathrm{GM}=\frac{I_{H}-I_{L}}{2 \nabla}
$$

In the second method, 10 metacentric heights are computed for the ship balanced in trim and sinkage in sinusoidal waves. The wave length is equal to the ship's length $L$ and the height is $h=S_{W} L$. The wave crest is centered at the longitudinal center of gravity and at each $L / 10$ forward and aft. We use the minimum and maximum values of GM to calculate $\Delta \mathrm{GM}$, as follows:

$$
\Delta \mathrm{GM}=\frac{\mathrm{GM}_{\max }-\mathrm{GM}_{\min }}{2}
$$

\subsubsection{Second level}

For the second level criterion, a probabilistic approach to the phenomenon is considered, by which a ship is found to be not vulnerable to parametric roll if the values of $\mathrm{C} 1$ and $\mathrm{C} 2$ are lower than $R_{\mathrm{PR} 0}=0.06$.

The value of $\mathrm{C} 1$ is computed as follows, based on a table that lists 16 weighted waves (Table 4, calculated from the wave scatter diagram using the method described in SDC 3/WP.5):

$$
\mathrm{Cl}=\sum_{i=1}^{16} W_{i} \cdot \mathrm{C}_{i}
$$

where $W_{i}$ is the wave weighting factor from Table 4 , and $\mathrm{C}_{\mathrm{i}}$ is equal to 0 if condition $\mathrm{A}$ or $\mathrm{B}$ is satisfied, and is equal to 1 otherwise.

Table 4 Wave cases for $\mathrm{C} 1$ coefficient of parametric roll level 2

\begin{tabular}{llll}
\hline $\begin{array}{l}\text { Wave } \\
\text { number } i\end{array}$ & Weight $W_{i}$ & $\begin{array}{l}\text { Wave length } \\
\lambda_{i} / \mathrm{m}\end{array}$ & $\begin{array}{l}\text { Wave height } \\
H_{i} / \mathrm{m}\end{array}$ \\
\hline 1 & 0.000013 & 22.574 & 0.350 \\
2 & 0.001654 & 37.316 & 0.495 \\
3 & 0.020912 & 55.743 & 0.857 \\
4 & 0.092799 & 77.857 & 1.295 \\
5 & 0.199218 & 103.655 & 1.732 \\
6 & 0.248788 & 133.139 & 2.205 \\
7 & 0.208699 & 166.309 & 2.697 \\
8 & 0.128984 & 203.164 & 3.176 \\
9 & 0.062446 & 243.705 & 3.625 \\
10 & 0.024790 & 287.931 & 4.040 \\
11 & 0.008367 & 335.843 & 4.421 \\
12 & 0.002473 & 387.440 & 4.769 \\
13 & 0.000658 & 442.723 & 5.097 \\
14 & 0.000158 & 501.691 & 5.370 \\
15 & 0.000034 & 564.345 & 5.621 \\
16 & 0.000007 & 630.684 & 5.950 \\
\hline
\end{tabular}

Condition A is as follows:

$$
\mathrm{GM}_{i}>0 \quad \text { and } \quad \frac{\Delta \mathrm{GM}_{i}}{\mathrm{GM}_{i}}<R_{\mathrm{PR}}
$$

with:

$\mathrm{GM}_{i}$ (m) average value of 10 metacentric heights computed for the wave number $i$, with the wave crest centered at the longitudinal center of gravity and at each $\lambda_{i} / 10$ forward and aft;

$\Delta \mathrm{GM}_{i}(\mathrm{~m})$ one-half of the difference between the maximum and minimum values of the 10 metacentric heights.

Condition B is as follows:

$$
V_{P R . i}>V_{S}
$$

with:

$V_{S} \quad(\mathrm{~m} / \mathrm{s}) \quad$ ship's speed;

$V_{P R . i}(\mathrm{~m} / \mathrm{s})$ reference speed corresponding to the parametric resonance conditions, calculated as follows:

$$
V_{P R . i}=\left|\frac{2 \lambda_{i}}{T_{0}} \sqrt{\frac{G M_{i}}{G M_{c}}}-\sqrt{g \frac{\lambda_{i}}{2 \pi}}\right|
$$

with:

$\lambda_{i} \quad$ (m) wave length (from Table 4);

$T_{0} \quad$ (s) natural roll period of the ship in calm water;

$\mathrm{GM}_{i}(\mathrm{~m})$ as defined above;

$\mathrm{GM}_{c}(\mathrm{~m}) \quad$ metacentric height in calm water.

The $\mathrm{C} 2$ coefficient is calculated from the maximum roll angle of the ship on each of the 197 non-zero-weighted waves of the wave scatter diagram (Table 2, or another table if the ship is sailing in a restricted area), considering seven speeds. For a given wave and a given speed, the maximum roll angle is the maximum absolute value of the solution $\Phi(\mathrm{t})$ of the differential equation of the parametric roll, which can be established as follows:

$$
J_{44} \ddot{\Phi}+B_{44} \dot{\Phi}+W \cdot \mathrm{GZ}(\Phi, t)=0
$$

with:

$\begin{array}{lll}\Phi & (\mathrm{rad}) & \begin{array}{l}\text { roll angle; } \\ \text { roll moment of inertia, including added } \\ \text { mass; } \\ J_{44}\end{array} \\ \left(\mathrm{~kg} \cdot \mathrm{m}^{2}\right) & \begin{array}{l}\text { damping coefficient; } \\ \text { ship's weight; }\end{array}\end{array}$

$\mathrm{GZ}(\Phi, t)(\mathrm{m}) \quad$ righting arm, function of roll angle $\Phi$ and time $t$, varying with the wave encounter frequency;

The $\mathrm{C} 2$ coefficient is calculated as follows:

$$
\mathrm{C} 2=\frac{1}{7} \sum_{i=1}^{197} \sum_{j=1}^{7} W_{i} . \mathrm{C} 2_{i, j}
$$

The weighting factor $W_{i}$ is extracted from the wave scattering table (Table 2). The coefficient $\mathrm{C} 2_{i, j}$ is equal to 1 if the maximum roll angle of the $\Phi(t)$ function solution of the differential equation for wave number $i$ and the speed $K_{j} V_{S}$ is higher than 25 degrees, and is 0 otherwise. The speed factors $K_{j}$ are given in Table 5 . 
Table 5 Speed factors $K_{j}$

\begin{tabular}{ll}
\hline Number $j$ & Speed factor $K_{j}$ \\
\hline 1 & -1 \\
2 & -0.866 \\
3 & -0.5 \\
4 & 0 \\
5 & 0.5 \\
6 & 0.866 \\
7 & 1 \\
\hline
\end{tabular}

Since there are a large number of non-zero-weighted waves in Table 2, the new regulation proposes the use of the Grim(1961) effective wave height concept to make the computation faster. This methodology is similar to that used for pure loss of stability. However, the effective height is considered to be one of the top $1 / 3$ highest waves, and is calculated as follows:

$$
H_{1 / 3}^{\text {eff }}=4.0043 \sqrt{m_{0}}
$$

The maximum roll angle $\Phi_{\max }$ is computed by solving the differential equation Eq. (25) for 10 effective waves whose heights are a fraction (from 0.1 to 1) of the maximum effective wave height, corresponding to the ship's length and the wave scatter diagram (Table 2). Linear interpolation is used to calculate the maximum roll angle associated with any effective wave height. Table 6 gives the effective wave heights (in meters) computed using the Grim method for all ships and associated with the waves of Table 2 that have a zero-crossing period $\left(T_{z}\right)$ equal to 10.5 seconds.

The future regulation proposes to calculate the maximum roll angle by analytically solving the differential equation. It also allows for a one-degree-of-freedom time domain simulation to solve the differential equation. Some solving conditions have recently been specified (initial roll angle, initial roll speed, time step, simulation duration, see SDC 3/WP.5). In this study, we used this second method, and specify below the methods used and the conditions for solving the differential equation and computing the value of $\mathrm{KG}_{\max }$.

\subsection{Maximum roll angle and $\mathrm{KG}_{\max }$ computation methods}

We have already presented the differential equation to be solved as Eq. (25) above.

\subsubsection{Moment of inertia}

We calculate the moment of inertia $J_{44}$ as follows:

$$
J_{44}=\Delta(1+a)(k B)^{2}
$$

with:

$\begin{array}{lll}\Delta & (\mathrm{kg}) & \text { ship's displacement; } \\ a & - & \text { added mass coefficient; } \\ k & - & \text { radius of inertia coefficient; } \\ B & (\mathrm{~m}) & \text { ship's breadth. }\end{array}$

Table 6 Effective height of the top 1/3 highest waves (m) for a zero-crossing period equal to 10.5 seconds

\begin{tabular}{llllll}
\hline$H_{S} / \mathrm{m}$ & Naval & \multicolumn{3}{l}{ Container Container Ro-Ro } & Tanker \\
& $L=142 \mathrm{~m}$ & $L=262 \mathrm{~m}$ & $L=319 \mathrm{~m}$ & $L=135 \mathrm{~m}$ & $L=227.5 \mathrm{~m}$ \\
\hline 0.5 & 0.288 & 0.362 & 0.361 & 0.280 & 0.353 \\
1.5 & 0.865 & 1.085 & 1.082 & 0.839 & 1.059 \\
2.5 & 1.442 & 1.809 & 1.804 & 1.399 & 1.764 \\
3.5 & 2.018 & 2.532 & 2.525 & 1.958 & 2.470 \\
4.5 & 2.595 & 3.256 & 3.247 & 2.518 & 3.176 \\
5.5 & 3.171 & 3.979 & 3.968 & 3.077 & 3.882 \\
6.5 & 3.748 & 4.703 & 4.690 & 3.637 & 4.587 \\
7.5 & 4.325 & 5.426 & 5.411 & 4.196 & 5.293 \\
8.5 & 4.901 & 6.149 & 6.133 & 4.756 & 5.999 \\
9.5 & 5.478 & 6.873 & 6.854 & 5.315 & 6.705 \\
10.5 & 6.054 & 7.596 & 7.576 & 5.875 & 7.410 \\
11.5 & 6.631 & 8.320 & 8.297 & 6.434 & 8.116 \\
12.5 & 7.208 & 9.043 & 9.019 & 6.993 & 8.822 \\
13.5 & 7.784 & 9.767 & 9.740 & 7.553 & 9.528 \\
14.5 & 8.361 & 10.490 & 10.462 & 8.112 & 10.234 \\
15.5 & 8.937 & 11.214 & 11.183 & 8.672 & 10.939 \\
16.5 & 9.514 & 11.937 & 11.905 & 9.231 & 11.645 \\
\hline & & & & &
\end{tabular}

The ship's natural roll period in calm water $\left(T_{0}\right)$ is linked to her moment of inertia, as follows:

$$
T_{0}=2 \pi \sqrt{\frac{J_{44}}{g \Delta \mathrm{GM}}}=2 \pi k B \sqrt{\frac{1+a}{g \mathrm{GM}}}
$$

with:

g $\quad 9.81 \mathrm{~m} / \mathrm{s}^{2}$ gravitational acceleration;

GM (m) metacentric height in calm water.

When the ship's roll period is known, we then choose the coefficients $a$ and $k$. If it is not known, we set coefficient $a$ to 0.1 and $k$ to 0.4 . The values of both $a$ and $k$ are given in Table 1 for all ships.

\subsubsection{Roll damping}

We calculate the roll damping coefficient $B_{44}$ using the method proposed by Kawahara et al. (2009), and take into account the ship's speed using the method proposed by Ikeda et al. (1978). The roll damping coefficient $B_{44}$ depends on the roll amplitude ( $\varphi_{a}$ in Kawahara et al., 2009). In this study, we pre-computed $B_{44}$ for 11 roll amplitude values from 1 to 50 degrees and used linear interpolation using the value of the current roll amplitude during the solving of the differential equation. The roll damping coefficient $B_{44}$ also depends on the distance between the center of gravity and the calm water surface (OG in Kawahara et al., 2009) and on the ship's roll period $\left(T_{0}\right)$. Both are linked to the KG. Thus, pre-computation of $B_{44}$ is required for all roll amplitudes in all iterations of the search for $\mathrm{KG}_{\max }$. 


\subsubsection{Righting arm}

We calculate the righting arm using a simplified method proposed by Peters et al. (2015) and the new regulation (SDC 3/WP.5, IMO, 2016), as follows:

$$
\mathrm{GZ}(\Phi)=\mathrm{GZ}_{0}(\Phi)-\left(\mathrm{GM}_{0}-\mathrm{GM}_{\text {moу }}-\Delta \mathrm{GM} \cdot \sin \left(\omega_{e} t\right)\right) \sin \Phi
$$

with:

$\mathrm{GZ}_{0}(\Phi)(\mathrm{m}) \quad$ righting arm in calm water associated with a user-fixed height of the center of gravity $\left(\mathrm{KG}_{0}\right)$;

$\mathrm{GM}_{0} \quad(\mathrm{~m}) \quad$ metacentric height in calm water associated with $\mathrm{KG}_{0}$.

$\mathrm{GM}_{\text {moy }}(\mathrm{m})$ average value of the metacentric height in waves, associated with the considered $\mathrm{KG}$, which may differ from $\mathrm{KG}_{0}$;

$\Delta \mathrm{GM} \quad(\mathrm{m}) \quad$ amplitude of the variation of the metacentric height in waves;

$\omega_{e} \quad(\mathrm{rad} / \mathrm{s})$ wave encounter frequency.

Belenky et al., (2011) demonstrated that this simplified method yields acceptable GZ values up to an angle of 30 degrees. Since the $\mathrm{C} 2$ coefficient is increased if the maximum roll angle exceeds 25 degrees, we can used this method in this study and it speeds up the computation of the maximum roll angle and $\mathrm{KG}_{\max }$. We pre-computed the righting arm in calm water $\left(\mathrm{GZ}_{0}\right)$ for heel angles from 0 to 50 degrees with a step of 5 degrees. During the simulation, we used linear interpolation to calculate its value for any roll angle $\Phi$. We computed $\mathrm{GM}_{\text {moy }}$ and $\Delta \mathrm{GM}$ before the simulation by computing the GM of the considered sinusoidal wave for 10 ship positions on the wave. $\mathrm{GM}_{\text {moy }}$ is the average value of the 10 metacentric heights. $\Delta \mathrm{GM}$ is half the difference between the maximum and minimum values. During the search for $\mathrm{KG}_{\max }$, we updated the value of $\mathrm{GM}_{\text {moy }}$ with the considered value of $\mathrm{KG}$.

We used $\mathrm{GM}_{\text {moy }}$ to calculate the ship's natural roll period $\mathrm{T}_{0}$, which is needed to calculate the damping coefficient $\mathrm{B}_{44}$. Thus, if $\mathrm{GM}_{\text {moy }}$ is negative, simulation is not possible and the $\mathrm{C} 2$ coefficient value is forced to 1 .

We calculated the wave encounter frequency $\omega_{\mathrm{e}}$ as follows:

$$
\omega_{e}=\omega_{w}\left(1+\omega_{w} \frac{K_{j} V_{s}}{g}\right)
$$

with:

$\omega_{w} \quad(\mathrm{rad} / \mathrm{s}) \quad$ wave frequency.

The positive values of the speed factors $K_{j}$ (from Table 5) correspond to head seas, and negative values correspond to following seas.

\subsubsection{Solving method}

To solve the differential equation, we used the Runge-Kutta $4^{\text {th }}$-order method.

\subsubsection{Initial conditions}

As proposed by Peters et al. (2015) and the new regulation (SDC 3/WP.5), the initial roll angle is equal to 5 degrees, and the initial roll speed is null.

\subsubsection{Simulation time}

The time duration of the simulation is equal to 15 times the ship's natural roll period, as also proposed by Peters et al. (2015) and the new regulation (SDC 3/WP.5). Computations performed with 10 and 20 roll periods give exactly the same value of $\mathrm{KG}_{\max }$, which proves that a time duration of 15 roll periods is long enough to attain a steady-state roll amplitude. The simulation is interrupted if the roll angle exceeds 50 degrees.

\subsubsection{Time step}

We set the time step to one $40^{\text {th }}$ of the ship's natural roll period, and validated this value by removing the damping and GM variation from the differential equation to simulate an undamped roll on calm water. The roll amplitude remained equal to the initial roll angle. This test fails if the Euler method, rather than the Runge-Kutta method, is used to solve the differential equation (the roll amplitude increases). Peters et al. (2015) and SDC 3/WP.5 propose a time step equal to one $30^{\text {th }}$ of the ship's natural roll period.

\subsubsection{Simulation implementation}

We performed the hydrostatic computations using Calcoque software (Grinnaert et al., 2015), with the water density equal to $1.025 \mathrm{t} / \mathrm{m}^{3}$. We also solved the differential equation and calculated the damping coefficient with this software to make a user-friendly computation of the C2 coefficient and the associated $\mathrm{KG}_{\max }$ curves.

\subsection{9 $K G_{\max }$ computation}

We determined the $\mathrm{KG}_{\max }$ associated with the $\mathrm{C} 2$ coefficient in two steps.

In the first step, we found the first value of KG for which the $\mathrm{C} 2$ coefficient is lower than $R_{\mathrm{PR} 0}$ and a second value of $\mathrm{KG}$ for which $\mathrm{C} 2$ is larger than $R_{\mathrm{PR} 0}$. To find this interval, we began with a low value of $\mathrm{KG}$ for which $\mathrm{C} 2$ is lower than $R_{\mathrm{PR} 0}$, near zero. We called this $\mathrm{KG}$ value the " $\mathrm{KG}$ starting value," denoted as "KG $\mathrm{K}_{\text {start". }}$. We then increased the value of $\mathrm{KG}$ by 10 centimeters in each iteration until $\mathrm{C} 2$ became higher than $R_{\text {PR } 0}$.

The second step is based on a classical dichotomy to find the highest value of $\mathrm{KG}$ that corresponds to a $\mathrm{C} 2$ value lower than $R_{\mathrm{PR} 0}$, at the required precision of $0.1 \mathrm{~mm}$. Since $\mathrm{C} 2$ is the sum of the weighting coefficients drawn from the IACS wave scatter diagram (number of occurrences of each wave in Table 2 divided by 100000 ), it is not possible to let the value of $\mathrm{C} 2$ be equal to $R_{\mathrm{PR} 0}$. Table 7 shows the values of $\mathrm{KG}$ and $\mathrm{C} 2$ while finding the $\mathrm{KG}_{\max }$ for the naval ship in this study, at a draft of $6.125 \mathrm{~m}$. The associated $\mathrm{KG}_{\max }$ is 9.2236 $\mathrm{m}$ (in gray in).

\subsection{Results}

We computed the $\mathrm{KG}_{\max }$ curves associated with the parametric roll levels 1 and 2 criteria for the five ships in this study, as shown in Fig. 9 to Fig. 13. The $\mathrm{KG}_{\max }$ curve determined by the first level-1 method (parallel water-plane) is marked "PR Level 1-1st method" (square markers), and that by the second level-1 method (ship balanced in trim and sinkage on a wave with the same length) is marked "PR Level 
1-2nd method" (round markers). The KG $\mathrm{K}_{\max }$ curve determined by the level-2 $\mathrm{C} 1$ criterion is marked "PR Level 2-C1" (solid line with diamond markers). The $\mathrm{KG}_{\max }$ curve determined by the level-2 $\mathrm{C} 2$ criterion is marked "PR Level 2-C2" (dashed line with diamond markers). Although coefficients $\mathrm{C} 1$ and $\mathrm{C} 2$ use the same criterion, they are considered as separate criteria in this paper. Based on our results, we can make following observations, some of which are similar to those observed for the pure loss of stability failure mode:

1) For the naval ship, the results of the two level-1 methods differ significantly.

2) The $K G_{\max }$ value determined by the second level-1 method is almost equal to that given by level-2 $\mathrm{C} 1$ for the naval ship and is close to that of the tanker.

3) For the Ro-Ro vessel, the level-2 C1 is somewhat more conservative than the second level-1 method.

4) Both first-level methods yield the same $K G_{\max }$ for the tanker at full load displacement and beyond. This result is as expected due to the cylindrical shape of the hull.

5) For the tanker, the criterion of the level- $2 \mathrm{C} 1$ is limited by the zero-GM at full load displacement and beyond (condition A, criterion $\mathrm{C} 1$ ).

6) The level-2 C2 curve of the tanker is fully coincident with that linked to KMT. This is due to the limit determined by the negative GMmoy (see subsection 4.2.3) and shows that the ship is not vulnerable to parametric roll.

7) Both curves given by the $\mathrm{C} 1$ and $\mathrm{C} 2$ criteria differ significantly for all ships (except for the tanker at full load displacement). The $\mathrm{C} 2$ criterion is always less conservative than $\mathrm{C} 1$.

8) The curve linked to the C2 criterion for the 319-m container ship has two peculiar jumps. A lesser jump occurs on the same curve for the C11 container ship (at full load displacement). This point is discussed in the next subsection.

9) According to these criteria, the naval ship and tanker are considered to be not vulnerable to parametric roll. The Ro-Ro vessel may also be considered to be not vulnerable because its highest $\mathrm{KG}_{\max }$ curve $(\mathrm{C} 2)$ has only one point below the curve given by the $1^{\text {st }}$-generation criteria, which may be lower if the weather criterion are taken into account. According to these criteria, both container ships are considered to be vulnerable. This confirms what is already known for the C11 (France et al., 2001).

\subsection{Focus on $\mathrm{C} 2$ criterion}

For any ship at any draft, the $\mathrm{KG}_{\max }$ linked to the $\mathrm{C} 2$ criterion is defined as the highest value of $\mathrm{KG}$ for which the value of $\mathrm{C} 2$ is lower than $R_{\mathrm{PR} 0}=0.06$. Thus, it is interesting to check the $\mathrm{C} 2$-versus-KG curve. These curves are shown in Fig. 14 to Fig. 18. For the three non-vulnerable ships (naval, Ro-Ro, tanker), we made the computations assuming a full load draft for an interval containing $\mathrm{KG}_{\max }$ with a step of 2 centimeters. For both container ships, we made the computations assuming a larger interval of KG with a step of 1 centimeter, at a draft of $9 \mathrm{~m}$ (C11 container ship, Fig. 15) and $12 \mathrm{~m}$ (319 m container ship, Fig. 16).
Table 7 Finding the value of KGmax

\begin{tabular}{|c|c|c|c|}
\hline \multicolumn{4}{|c|}{ First step: finding the interval } \\
\hline Iteration & $\mathrm{KG}(\mathrm{m})$ & $\mathrm{C} 2$ & $\mathrm{C} 2<R_{\mathrm{PR} 0}$ \\
\hline 1 & $\mathrm{KG}_{\text {start }}=7$ & 0 & $\mathrm{Y}$ \\
\hline 2 & 7.1 & 0 & $\mathrm{Y}$ \\
\hline 3 & 7.2 & 0 & $\mathrm{Y}$ \\
\hline 4 & 7.3 & 0 & $\mathrm{Y}$ \\
\hline 5 & 7.4 & 0 & $\mathrm{Y}$ \\
\hline 6 & 7.5 & 0 & $\mathrm{Y}$ \\
\hline 7 & 7.6 & 0 & $\mathrm{Y}$ \\
\hline 8 & 7.7 & 0 & $\mathrm{Y}$ \\
\hline 9 & 7.8 & $2.86 \mathrm{E}-07$ & $\mathrm{Y}$ \\
\hline 10 & 7.9 & $1.57 \mathrm{E}-06$ & $\mathrm{Y}$ \\
\hline 11 & 8.0 & 4.29E-07 & $\mathrm{Y}$ \\
\hline 12 & 8.1 & 0 & $\mathrm{Y}$ \\
\hline 13 & 8.2 & 0 & $\mathrm{Y}$ \\
\hline 14 & 8.3 & 0 & $\mathrm{Y}$ \\
\hline 15 & 8.4 & 0 & $\mathrm{Y}$ \\
\hline 16 & 8.5 & 0 & $\mathrm{Y}$ \\
\hline 17 & 8.6 & $2.49 \mathrm{E}-05$ & $\mathrm{Y}$ \\
\hline 18 & 8.7 & 0.0293483 & $\mathrm{Y}$ \\
\hline 19 & 8.8 & 0.017636 & $\mathrm{Y}$ \\
\hline 20 & 8.9 & 0.00266057 & $\mathrm{Y}$ \\
\hline 21 & 9.0 & 0.000234857 & $\mathrm{Y}$ \\
\hline 22 & 9.1 & $3.13 \mathrm{E}-05$ & $\mathrm{Y}$ \\
\hline 23 & 9.2 & 0.0219234 & $\mathrm{Y}$ \\
\hline 24 & 9.3 & 0.154703 & $\mathrm{~N}$ \\
\hline \multicolumn{4}{|c|}{ Second step: dichotomy } \\
\hline Iteration & $\mathrm{KG}(\mathrm{m})$ & $\mathrm{C} 2$ & $\mathrm{C} 2<R_{\mathrm{PR} 0}$ \\
\hline 25 & 9.25 & 0.0760626 & $\mathrm{~N}$ \\
\hline 26 & 9.225 & 0.0749527 & $\mathrm{~N}$ \\
\hline 27 & 9.2125 & 0.0371166 & $\mathrm{Y}$ \\
\hline 28 & 9.21875 & 0.0449244 & $\mathrm{Y}$ \\
\hline 29 & 9.22188 & 0.0462103 & $\mathrm{Y}$ \\
\hline 30 & 9.22344 & 0.0464114 & $\mathrm{Y}$ \\
\hline 31 & 9.22422 & 0.07403 & $\mathrm{~N}$ \\
\hline 32 & 9.22383 & 0.0740291 & $\mathrm{~N}$ \\
\hline 33 & 9.22363 & 0.0502479 & $\mathrm{Y}$ \\
\hline 34 & 9.22373 & 0.0740291 & $\mathrm{~N}$ \\
\hline
\end{tabular}




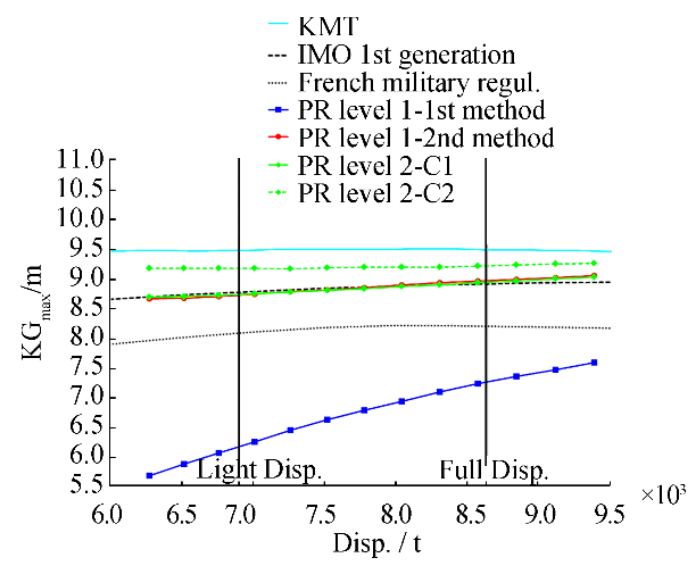

Fig. $9 \mathrm{KG}_{\max }$ curves associated with the parametric roll criteria for the naval ship

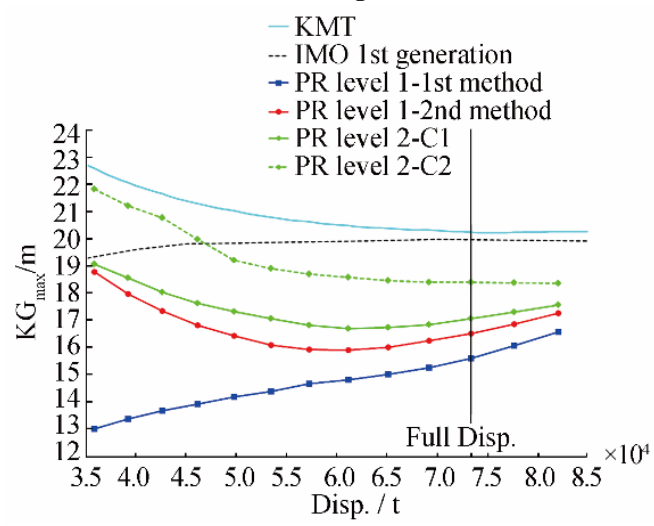

Fig. 10 KGmax curves associated with the parametric roll criteria for the $\mathrm{C} 11$ container ship

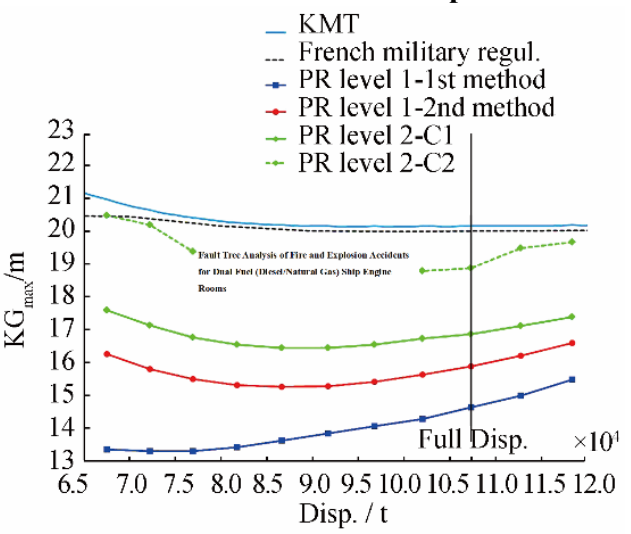

Fig. $11 \mathrm{KG}_{\max }$ curves associated with the parametric roll criteria for the $319 \mathrm{~m}$ container ship

Fig. 18 shows the curve of the tanker, for which $\mathrm{C} 2$ is equal to 0 for all values of $\mathrm{KG}$ lower than $\mathrm{KG}_{\max }(13.70 \mathrm{~m})$ and is equal to 1 for all higher values. This shows that a parametric roll never occurs on this ship. The value of $\mathrm{C} 2$ is forced to 1 when the average value of GM on waves becomes negative (see subsection 4.2.3).

Fig. 14 shows the curve for the naval ship, where we observe a small interval of $\mathrm{KG}$ (centered approximatively at $8.70 \mathrm{~m}$ ) in which the $\mathrm{C} 2$ coefficient is not null. This shows that a parametric roll occurs for some lightly weighted waves that correspond with the ship's natural roll period. For higher values of $\mathrm{KG}, \mathrm{C} 2$ reduces to near zero and then rapidly increases to 1 . While parametric roll occurs in these $\mathrm{KG}$ conditions, the average value of GM is near zero: the ship becomes statically unstable on waves.

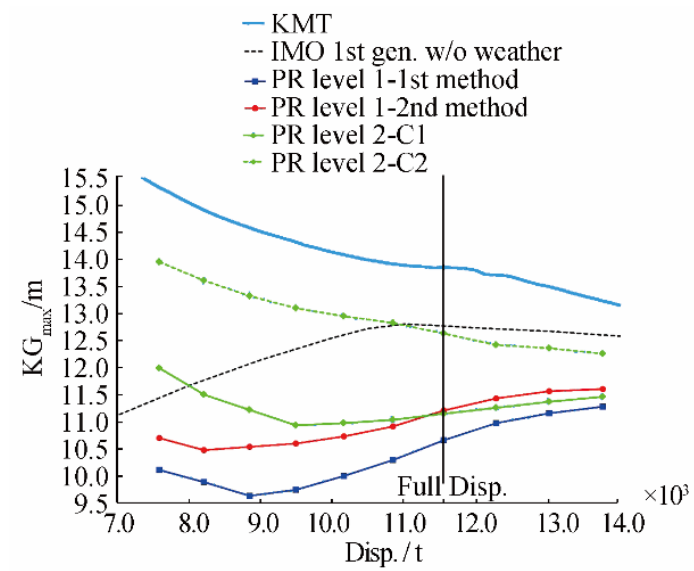

Fig. $12 \mathrm{KG}_{\max }$ curves associated with the parametric roll criteria for the Ro-Ro vessel

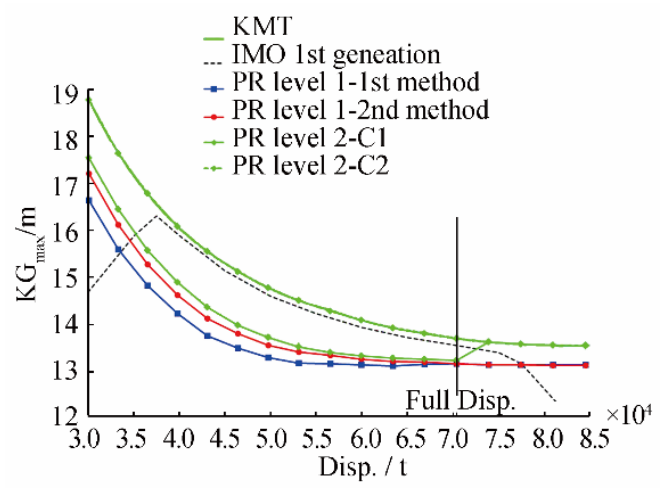

Fig. $13 \mathrm{KG}_{\max }$ curves associated with the parametric roll criteria for the tanker ( $\mathrm{C} 2$ and KMT curves are fully coincident)

Fig. 17 shows the C2-versus-KG curve for the Ro-Ro vessel, from which we observe that the increasing part of the curve is longer than both the tanker and naval ship. We also observe that two values of $\mathrm{KG}$ larger than $\mathrm{KG}_{\max }(12.57 \mathrm{~m})$ give values of $\mathrm{C} 2$ that are lower than $R_{\mathrm{PR} 0}(\mathrm{KG}=12.60$ and $12.62 \mathrm{~m}$, marked with * on Fig. 17).

Fig. 15 and Fig. 16 show the same curves, respectively, for the $\mathrm{C} 11$ and $319 \mathrm{~m}$ container ships. On both, we observe many peaks and relatively large intervals of $\mathrm{KG}$ larger than $\mathrm{KG}_{\max }$, for which the value of $\mathrm{C} 2$ is lower than $R_{\mathrm{PR} 0}$, thus fulfilling the associated criterion. These intervals are colored in gray on the corresponding figures. This non-monotonically increasing configuration of the $\mathrm{C} 2$ curve makes the starting value of $\mathrm{KG}\left(\mathrm{KG}_{\text {start }}\right.$ in this paper, $15 \mathrm{~m}$ for both container ships) very important in the search for $\mathrm{KG}_{\text {max }}$. The value of the increment used in this search (10 centimeters in this study) is also very important. Both parameters must be chosen such that they avoid overlooking a small zone of $\mathrm{KG}$ for which $\mathrm{C} 2$ is larger than $\mathrm{R}_{\mathrm{PR} 0}$. The 
computation of the $\mathrm{C} 2$-versus-KG curves for all drafts makes it possible to define authorized and restricted areas according to the $\mathrm{C} 2$ criterion. Fig. 19 and Fig. 20 show these zones for both container ships (authorized areas in white, restricted areas in gray). The lower envelopes of the restricted areas give the $\mathrm{KG}_{\max }$ curves linked to $\mathrm{C} 2$ that are shown in Fig. 10 and Fig. 11. The jumps observed on these curves correspond to the passage from the upper to the lower restricted area (at drafts equal to 10 and $13 \mathrm{~m}$ for the 319 m container ship).

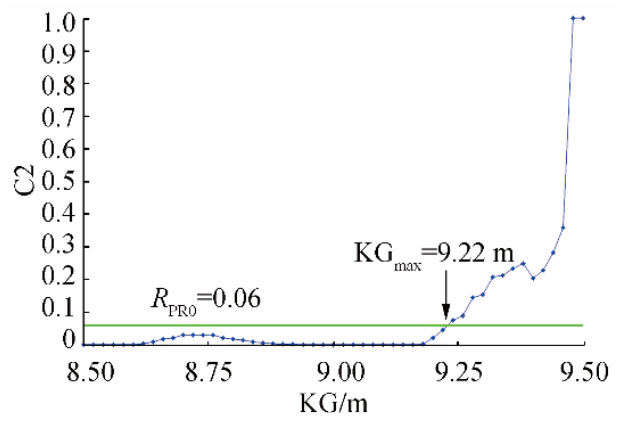

Fig. 14 Curve C2 versus KG for the naval ship $(d=6.125 \mathrm{~m})$

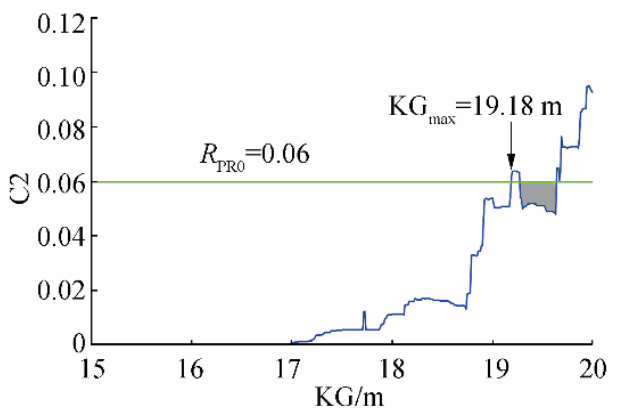

Fig. 15 Curve $\mathrm{C2}$ versus KG for the C11 container ship $(d=9.00 \mathrm{~m})$

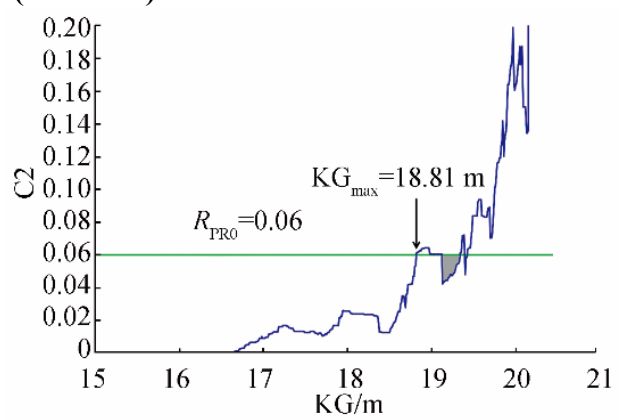

Fig. 16 Curve $\mathrm{C} 2$ versus KG for the $319 \mathrm{~m}$ container ship $(d=12.00 \mathrm{~m})$

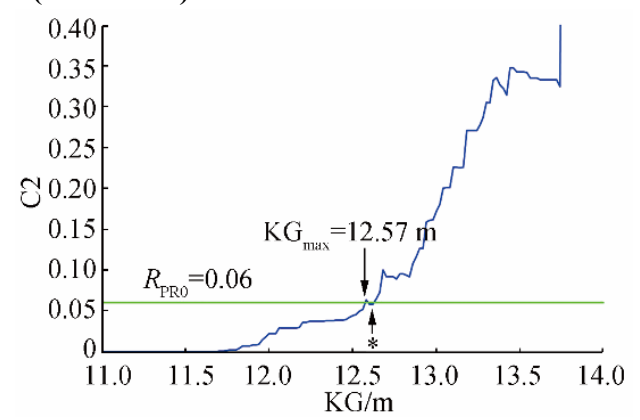

Fig. 17 Curve C2 versus KG for the Ro-Ro vessel $(d=5.50 \mathrm{~m})$

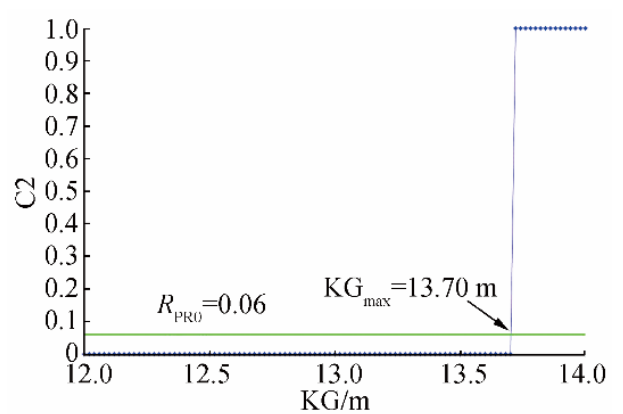

Fig. 18 Curve C2 versus KG for the tanker $(d=11.00 \mathrm{~m})$

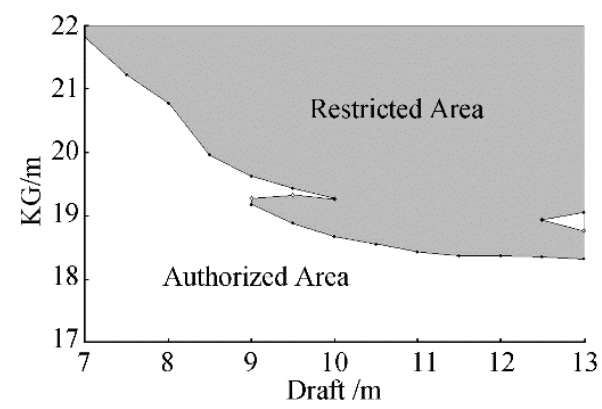

Fig. 19 Authorized and restricted areas according to the $\mathrm{C2}$ criterion for the $\mathrm{C} 11$ container ship

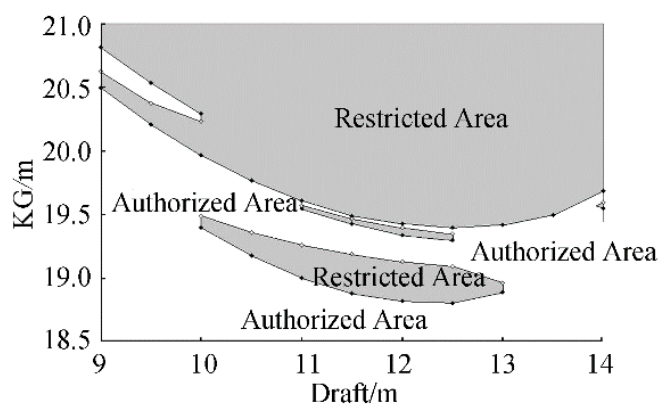

Fig. 20 Authorized and restricted areas according to the $\mathrm{C} 2$ criterion for the $319 \mathrm{~m}$ container ship

\section{Conclusions}

In this study, we computed the $\mathrm{KG}_{\max }$ curves associated with the level-1 and level-2 criteria of pure loss of stability and parametric roll failure modes for five ships of different types. The results reveal that level-2 criteria can be more conservative than the second level-1 method for both failure modes. This configuration is not anticipated in the future regulation. The results also show that the discrepancy between the level-1 methods can be very large, especially for the pure loss of stability failure mode. We argue that the safety margins ensured by the first level-1 method (parallel water-plane) seem to be excessive and may conflict with the future excessive acceleration criteria. Thus, if equipped to make hydrostatic computations on waves, naval architects and shipyards should not use the first level-1 method. However, this method could have real added value if it ensures an acceptable safety margin for small vessels, which are likely to be designed by architects of modest means. 
The computation results of the second check of the parametric roll level-2 criterion (C2) for all possible values of KG shows that the more vulnerable the ship is to this failure mode, the more her C2-versus-KG curve is characterized by peaks and a long interval of $\mathrm{C} 2$ going from 0 to 1 . This makes the surface formed by both the draft and $\mathrm{KG}$ foliated with both authorized and restricted zones. Consequently, it is not sufficient to check that $\mathrm{C} 2$ is lower than RPRo for a given ship's loading condition. It is necessary to check this condition for all lower values of $\mathrm{KG}$. We recommend that the future regulation clearly specify the requirement for this additional check.

The $\mathrm{KG}_{\max }$ curves associated with the parametric roll criteria confirm the well-known vulnerability of the C11 container ship to this failure mode.

\section{Acknowledgements}

The authors would like to acknowledge Clève Wandji (Bureau Veritas), Philippe Corrignan (Bureau Veritas), and Jean-François Leguen (DGA/TH) for their valuable discussions during the preparation of this paper.

\section{References}

Bassler C, Belenky V, Bulian G, Francescutto A, Spyrou K, Umeda $\mathrm{N}, 2009$. A review of available methods for application to second level vulnerability criteria. 10th International Conference on Stability of Ships and Ocean Vehicles, St Petersburg, 111-128.

Belenky V, Bassler C, Spyrou K, 2011. Development of second generation intact stability criteria. US Navy, Naval Surface Warfare Center Carderock Division, NSWCCD-50-TR-2011/065.

Bulian G, Francescutto A, 2011. Considerations on parametric roll and dead ship conditions for the development of second generation intact stability criteria, 12th International Ship Stability Workshop, Washington, 7-18.

Direction Générale de l'Armement, Instruction générale n 6018 A. (1999). Stabilité des bâtiments de surface de la marine nationale. (restricted diffusion, in French)

France WN, Levadou M, Treakle TW, Paulling JR, Michel RK, Moore C, 2001. An investigation of head-sea parametric rolling and its influence on container lashing systems. SNAME Annual Meeting.

Francescutto A, Umeda N, 2010. Current status of new generation intact stability criteria development. 11th International Ship Stability Workshop, Wageningen, 1-5.

Garme K, 1997. Model seakeeping experiments presented in the time-domain to facilitate validation of computational tool. Kungl Tekniska Högskolan, Stockolm.

Grim O, 1961. Beitrag zu dem problem der Sicherheit des Schiffes im seegang. Schiff und Hafen, Heft 6, S. 490-497.

Grinnaert F, Billard JY, Laurens JM, 2015. Calcoque: a fully 3D ship hydrostatic solver. 12th International Conference on the Stability of Ships and Ocean Vehicles, Glasgow.

Grinnaert F, Laurens JM, 2013. Stabilité du navire - Théorie, réglementation, méthodes de calcul - Cours et exercices corrigés. Ellipses, collection Technosup. (in French)
International Association of Classification Societies, 2001. Rec. No. 34. Standard Wave Data, Rev.1.

Ikeda Y, Himeno Y, Tanaka N, 1978. Components of roll damping of ship at forward speed. Department of Naval Architecture University of Osaka Prefecture, Report No 404.

International Maritime Organization, 2012. SLF ISCG 54/19. Proposal of revision of updated draft vulnerability criteria of levels 1 and 2 for the failure modes of pure loss of stability and parametric roll. Submitted by Japan 29 May 2012.

International Maritime Organization, 2013. SDC 1/INF.8. Information collected by the Correspondence Group on Intact Stability regarding the second generation intact stability criteria development. Submitted by Japan 13 November 2013.

International Maritime Organization, 2015. SDC 2/WP.4, $2^{\text {nd }}$ session. Development of Second Generation Intact Stability Criteria, Development of Amendments to Part B of the 2008 IS Code on Towing and Anchor Handling Operations.

International Maritime Organization, 2016. SDC 3/WP.5, $3^{\text {rd }}$ session. Finalization of Second Generation Intact Stability Criteria, Amendments to Part B of the 2008 IS Code on Towing, Lifting and Anchor Handling Operations.

International Maritime Organization, 2009. International code of intact stability, 2008. London.

Kaufmann J, 2009. Fatal Accident on Board the CMV Chicago Express During Typhoon "Hugupit" on September 242008 off the Coast of Hong Kong. Bundesstelle für Seeunfalluntersuchung. Investigation Report 510/08.

Kawahara Y, Maekawa K, Ikeda Y, 2009. A simple prediction formula of roll damping of conventional cargo ships on the basis of Ikeda's method and its limitation. $10^{\text {th }}$ International Conference on Stability of Ships and Ocean Vehicles, St Petersburg.

Krueger S, Hatecke H, Billerbeck H, Bruns A, Kluwe F, 2013. Investigation of the 2nd generation of intact stability criteria for ships vulnerable to parametric rolling in following seas. $32^{\text {nd }}$ International Conference on Ocean, Offshore and Arctic Engineering OMAE2013, Nantes.

Krueger S, Hatecke H, Gualeni P, Di Donato L, 2015. On the application of the $2^{\text {nd }}$ generation intact stability criteria to Ro-Pax and container vessels. 12th International Conference on the Stability of Ships and Ocean Vehicles, Glasgow.

Moelgaard A, 2000. PMM-tests with a model of a frigate class DDG-51. Danish Maritime Institute 2000071, Report No. 1.

Peters W, Belenky V, Chouliaras S, Spyrou K, 2015. Requirements for computational methods to be used for the IMO second generation intact stability criteria. $12^{\text {th }}$ International Conference on the Stability of Ships and Ocean Vehicles, Glasgow.

Umeda N, 2013. Current status of second generation intact stability criteria development and some recent efforts. 13th International Ship Stability Workshop, Brest, 138-157.

Wandji C, Corrignan P, 2012. Test application of second generation IMO intact stability criteria on a large sample of ships. 11th International Conference on the Stability of Ships and Ocean Vehicles, Athens, 129-139. 